record card) was issued in only $59.26 \%$ of cases. Regarding to the accidents, $58.45 \%$ occurred in employer's facilities, during the day, predominantly between 9 and $10 \mathrm{am}$. Of those, $73.95 \%$ were typical, $21.54 \%$ were in transit, and almost all (94.64\%) of injured workers needed medical attention. The accidents were mainly caused by external causes of accidental injury (53.10\%) and by accidents $(24.58 \%)$. Most affected body parts were hands (37.16\%). About cases evolution, $56.38 \%$ of workers were temporarily disabled and $9.74 \%$ died due to the accident.

Conclusions Accidents at work cause serious social and economic damages, mental and emotional harm to workers, their family and dependents. To the Public Health, accidents at work involve spending on emergency, assistance, and rehabilitation; to country's economy, workers in productive age are lost.

\section{RELATIONS BETWEEN WORK ENVIRONMENT FACTORS, BURNOUT AND HEALTH OF THE MILITARY PERSONNEL}

E M Merisalu, Viin, Vähi, Jõgeva, Orru. University of Tartu, Tartu, Estonia

10.1136/oemed-2013-101717.148

Aim The purpose of present study was to examine relations between work environment factors, burnout and state of health of the military personnel and to find factors that can affect the level of burnout and adverse health status.

Method The data has been gathered by the anonymous questionnaire in 2008-2009. The target group consisted of 3199 military men. Six structural units were included into the study. Results Study group consisted of 641 persons, whereas $45 \%$ of them were servants, $31 \%$ executive officers and $20 \%$ officers (4\% unknown). $55 \%$ of respondents were female (mainly servants) and 44\% men (mainly officers). The average age of the study group was 39 years (SD 11) and their average work experience 6 years ( $\max 40 \mathrm{yrs}$ ).

In general military personnel found their health to be good and they were fairly satisfied with their working environment. But the respondents with higher burnout levels assessed more negatively their work environment and health status. They perceived more often work-family conflict, lack of instructions, lower appreciation and less internest toward work. Also, they measured deeper tiredness and depression and more psycosomatic disorders. Male officers and female servants were more negative in their answers than male noncommissioned officers and male servants.

Conclusions That to prevent burnout and health problems among military personnel it is needful to pay more attention on work environment and work organisation.

\section{Session: T. Intervention studies \& health management}

\section{IMPROVING THE IMPACT: RECOMMENDATIONS FOR THE USE OF CLEANING CHEMICALS}

${ }^{1} \mathrm{P}$ K Henneberger, ${ }^{2} \mathrm{~K}$ Fagan, ${ }^{1} \mathrm{~S}$ A Henn. ${ }^{1}$ National Institute for Occupational Safety and Health, Morgantown, WV, United States of America; ${ }^{2}$ Occupational Safety and Health Administration, Washington, DC, United States of America

10.1136/oemed-2013-101717.149

Objectives Cleaning chemicals are commonly used in the occupational environment and have been associated with increased risks of asthma, upper and lower respiratory symptoms, and dermatitis. It is important that cleaning workers use appropriate products safely. The Occupational Safety and Health Administration (OSHA) and the National Institute for Occupational Safety and Health (NIOSH) in the United States collaborated to develop educational materials targeted at workers that use cleaning chemicals and their employers.

Methods OSHA and NIOSH staff used published data about cleaning chemicals to guide the content of an information sheet and poster, sought input from industry, unions, government and academia, and developed plans for dissemination of these educational materials.

Results The information sheet and poster were released to the public in 2012 and are electronically available on the OSHA and NIOSH websites. The information sheet, developed for employers, is 6 pages and includes sections on choosing safer cleaning chemicals, safer work practices, worker training, and resources, including numerous links to sites on the internet that have additional information. The poster, developed for workers, alerts workers to the potentially harmful effects of cleaning chemicals and what they need to know to work safely with these chemicals. The poster, originally in English, has been translated into Spanish, Chinese, and Tagalog, and can be printed in varying sizes. The educational materials were disseminated through a network of partnerships created by the NIOSH National Occupational Research Agenda that included unions, safety and health professionals, worker organizations, academia, and government agencies.

Conclusions The information sheet and poster have filled a need for clear communication about chemical cleaners that workers handle every day. Efforts to further disseminate these materials are still underway. Additional feedback from stakeholders will determine if additional translated languages are needed.

\section{INDEPENDENT MEDICAL EVALUATIONS: A SYSTEMATIC REVIEW}

1J W B Busse, 'Ebrahim, ${ }^{2}$ Mahood, 'Guyatt, ${ }^{3}$ Kunz. ${ }^{1}$ McMaster University, Hamilton, Canada; ${ }^{2}$ nnstitute for Work \& Health, Toronto, Canada; ${ }^{3}$ University Hospital Basel, Basel, Switzerland

\subsection{6/oemed-2013-101717.150}

Objective Individuals suffering an injury or illness may be eligible to receive financial compensation based on their level of impairment and an independent medical evaluation (IME) often guides this determination. Our objectives are to determine the issues authors have addressed and their viewpoints, establish where evidence allows for recommendations regarding the best practices for IMEs, identify important gaps, and provide guidance on priorities for future research.

Methods We conducted a systematic review of all literature regarding IMEs conducted in a North American setting.

Results We identified 4667 potentially eligible studies; we retrieved 129 studies in full text and 88 proved eligible. We located another 22 eligible articles from bibliography searches. The chance-independent between-reviewer agreement (phi) on full text eligibility was 0.84 . The majority of studies $(81 \% ; 89$ of 110) were narrative reviews.

We found that authors of narrative reviews are much more likely to express favourable views if they perform IMEs, work for a company that arranges these assessments, or work in an area in which IMEs disputing patient's reported level of impairment are likely to be helpful (Pearson correlation coefficient $=$ $0.70, \mathrm{p}<0.001)$. The 8 reasons provided for which IMEs are 